\title{
Evolving a core-periphery pattern of manufacturing industries across Chinese provinces
}

\author{
MAO Qiliang ${ }^{1,2}$, WANG Fei ${ }^{1,2}$, LI Jun $^{1,2}$, DONG Suocheng ${ }^{1}$ \\ 1. Institute of Geographic Sciences and Natural Resources Research, CAS, Beijing 100101, China; \\ 2. University of Chinese Academy of Sciences, Beijing 100049, China
}

\begin{abstract}
This paper, concerning uneven development in China, empirically analyzes the core-periphery gradient of manufacturing industries across provinces (autonomous regions, municipalities), and assesses the extent to which these provinces have changed in recent years. Since China's reform and opening-up, the spatial structure of the economy has presented a significant core-periphery pattern, the core evidently skewing towards east-coastal areas. With the deepening of market reforms and expansion of globalization, industrial location is gradually in line with the development advantages of provinces. The core provinces specialize in those industries characterized by strong forward and backward linkages, as well as a high consumption ratio, a high degree of increasing returns to scale, and labor or human-capital intensity. However, it is the opposite with regard to peripheral provinces, in addition, energy intensive industries are gradually concentrating in these areas. To a certain degree, the comparative advantage theory and new economic geography identify the underlying forces that determine the spatial distribution of manufacturing industries in China. This paper indicates that the industrialization of regions along different gradients becomes unsynchronized will be a long-term trend. Within a certain period, regions are bound to develop industrial sectors in line with their respective characteristics and development stage. A core-periphery pattern of industries also indicates that industrial development differentials across regions arise because of not only the uneven distribution of industries but also the inconsistent evolving trends of industrial structure for each province.
\end{abstract}

Keywords: core-periphery pattern; spatial distribution; manufacturing industries; regional characteristic; industrial characteristic

\section{Introduction}

China has shifted to a market-oriented economy from a planned economy subsequent to reforms and opening-up. Since then, the spatial distribution of industries has been mainly driven by regional advantages, as market mechanisms have prevailed in the spatial allocation of resources. China is the most populous developing country, with inherent regional differences in geography, history, and culture (Huang and Huang, 2008). Although the Chi-

Received: 2014-01-15 Accepted: 2014-02-16

Foundation: National Science and Technology Infrastructure Program of China, No.2007FY110300

Author: Mao Qiliang, PhD, specialized in regional economics and industrial location. E-mail: more1987@163.com 
nese economy has grown rapidly for long, there remains significant divergence in regional development and evident economic spatial hierarchies in the form of core and periphery patterns in the economic landscape. So, what are the features of the core-periphery pattern in China? What is the industrial specialization for each region, and how has the situation evolved? An investigation into these questions would lead to the recognition that the spatial division of production in China differs according to the stage of development, and is in concordance with policy implications with respect to industrial restructuring, financial transfers, and so on.

Studies on core-periphery gradients in industrial location patterns across regions at different degrees of development could be traced to Vernon's (1966) product life cycle theory, which explains the spatial distribution of industries between high gradient countries and low gradient countries in view of the different stages of industries and their products. Kojima (2000) improved upon the "flying geese paradigm" to explain the evolution of the global division of production, and the course of industrial relocation from Japan to East and Southeast Asia. Both theories are based on the framework of comparative advantage, and the only important difference between them is that the product life cycle theory focuses on advanced countries, whereas the "flying geese paradigm" focuses on developing countries. A combination of them leads to the general rule of global division and industry transfer caused by evolving comparative advantage between countries. Deviating from the comparative advantage paradigm, which considers industrial location as exogenous, the new economic geography considers industrial location to be endogenous, based on location decisions made by firms and consumers (Combes and Lafourcade, 2011). The new economic geography presents a general equilibrium framework for understanding the core-periphery pattern, and indicates that industrial location is a result of the interaction between the forces of regional agglomeration and dispersion. When a region possesses an initial development advantage, production factors and economic activities agglomerate through mechanisms of positive feedback, as a result of which a core-periphery pattern is formed, with central and peripheral regions displaying a high and low degree of industrialization, respectively.

The evolution of industrial structure follows universal rules for each region (Lu, 1995). The evolution of industrial structure between core and periphery countries usually follows that countries typically develop through the production of certain goods, and then "upscale" as they cede those sectors to the nations that follow (Fujita et al., 1999). In other words, industrial spatial pattern is based on production features and differences in regional advantage; thus, different regions develop industries according to their own advantages in the spatial division of production. As Bottazzi et al. (2008) proposed, different locations exert different structural influences on the distribution of industries. The core-periphery pattern is a universal phenomenon in North America and Europe. Combes and Overman (2004) found that both economic activities and the population of the EU are concentrated in the "blue banana" area, which has become the "center" of the EU. Although development levels among regions have been somewhat converging, the core-periphery pattern has still been steady. Midelfart-Knarvik et al. (2000) found some obvious phenomena in the internal industrial distribution within the EU, for example, unskilled labor-intensive industries clustering in the periphery because of low wage levels; $R \& D$ intensive industries clustering in the center with abundant research staff; industries with high backward-forward linkages being sensitive to 
regional gradient in the core-periphery pattern; and central countries being attracted to industries relying heavily on intermediate inputs or having high levels of economic scale. Brülhart and Traeger (2005) found similar core-periphery gradients in sectoral location patterns within the EU. Holmes and Stevens (2004) detected differentiated industrial structures across regions, in line with the core-periphery gradient of urbanization in the U.S. Vogialtzoglou (2006) investigated changes in industrial spatial distribution of NAFTA and found specialization between countries, with manufacturing industries transferring to Mexico (the periphery) from the U.S. (the core), especially labor-intensive and low-tech industries.

Empirical studies on industrial spatial patterns are not as plentiful as theoretical studies, and they mainly focus on developed countries or regions other than developing countries. In this sense, studying the case of China becomes meaningful, as it is a large developing country and economic spatial patterns have changed a lot owing to uneven development among regions in past years. This case helps to understand deeply how the general law of economic geography works.

After 1978, the spatial pattern of industry in China changed significantly because of market-oriented reforms and globalization. Studies on spatial distribution of industries are basically based on the views of regional specialization and industrial agglomeration. Many studies indicate industrial concentration as the primal feature, a view that has been reinforced corresponding to the progress of market-oriented reforms (Fujita and $\mathrm{Hu}, 2001$; Wen, 2004; He et al., 2008). Meanwhile, regions have become specialized since the late 1990s (Wei and Zhou, 2008), and He and Xie (2006) found significant spatial differences in manufacturing, especially in export, material, consumer market and high profit oriented industries. Specifically, $\mathrm{Wu}$ and $\mathrm{Li}$ (2010) found labor-intensive manufacturing clustering along the southeastern coast, while resource intensive manufacturing clustered in northern China and central and western regions. In recent years, the spread of industries from east to west has occurred, reinforcing the specialization between core and peripheral regions to a certain extent. He and Wang (2012) found labor-intensive industries transferred from coastal to central regions, and Feng (2010) argued that industrial spatial transfers also occurred in resource-dependent and resource-intensive industries.

These studies explain the change in industrial spatial patterns based on the paradigm of comparative advantage and the new economic geography. Market-oriented reforms and opening-up policy are the catalysts that provoke industries to advantageously relocate across regions and form new industrial spatial patterns. Human capital, labor costs, and natural resources are important locational factors (Wu and Li, 2010). However, Bao et al. (2012) have argued that new economic geography better explains the evolution of industrial spatial patterns, compared to traditional trade theory. Owing to globalization, coastal areas are able to tap their geographical advantage for industrial agglomeration (Jin et al., 2006), and international trade can affect the industrial distribution in China (Huang and Li, 2006). Through mechanisms such as cumulative causation, agglomeration forces of the home market effect, backward-forward linkages, and technology spillovers that enable further agglomeration, economic patterns are shaped.

Contemporary studies provide many meaningful conclusions on industrial spatial distribution in China. However, they are insufficient as they focus on the view of the aggregate, but not on specific features and changing trends. China is a unique developing country, with 
the unequal distribution of industries being the result of the movement of factors of production due to footloose industrial reallocation and asynchronous development in regions. Therefore, it becomes necessary to study the features of industrial spatial distribution in China from the perspective of regional economic gradient differences. Consequently, this paper demonstrates the core-periphery pattern of industries across provinces based on regional economic gradients. The structure of the paper is arranged as follows: the second part describes data and research methodology, the third part descriptively portrays the core-periphery pattern of China, and core-periphery gradient of industrial spatial distribution, and the fourth part summarizes the paper and discusses corresponding policies.

\section{Methodology and data sources}

\subsection{Core-periphery pattern and hypotheses for regional specialization}

Core and periphery regions have different agglomeration and dispersion forces in different industries. In core regions, enterprises benefit from large markets, better input-output linkages, and agglomeration externalities (such as MARS and Jacobs externalities), but they also have to bear the high price of production factors and crowded development spaces. Correspondingly, in peripheral regions, although enterprises benefit from low price of production factors and larger development spaces, they miss out on the positive externalities of core regions.

Krugman (1991) proved in the two-region model that because of the interaction of increasing returns and transport costs, footloose companies will tend to locate in core regions with large markets (backward linkages), and workers as consumers will purchase commodities at lower transport costs in these regions. Consumers tend to work and live there with the benefits of lower price and higher real wage (forward linkages), so that it promotes industrial agglomeration in core regions. Venables (1996) used an understanding based on linkages of upstream and downstream industry, instead of labor transfer as in Krugman (1991). Considering transport costs, upstream industries become attracted to regions where several downstream industries are already located. Meanwhile, upstream industries will appeal downstream to locate. The intermediate-input intensive industry and upstream industry of manufacturing are inclined to locate in regions with better manufacturing bases. Klein et al. (2012) confirmed the validity of the new economic geography by explaining the persistence of the manufacturing belt in the US. The results show that market potential was central to the existence of the manufacturing belt, that it mattered more than factor endowments, and that its impact came through interactions both with scale economies and with linkage effects.

Generally speaking, core and periphery regions affect spatial distribution of industries through scale economies, market potential, and input-output linkages between industries.

Hypothesis 1: Intermediate-input intensive industry tends to locate in core regions with a better manufacturing base because of input transport cost saving.

Hypothesis 2: Upstream industry of manufacturing tends to locate in core regions with a better manufacturing base because of output transport cost saving.

Hypothesis 3: Industries with increasing returns to scale tend to locate in core regions with large market potential and better infrastructure.

In order to control effects of other factors and enhance the estimation accuracy of the 
model, traditional trade theory and special features of China should be considered.

Traditional trade theory emphasizes industrial structure of a region. Specialization is determined first by resource endowment, technology, and policy. As it is hard to measure factors such as technology, consumer preference, and so on, this paper only considers differences in resource endowment. Core and periphery differ in labor and capital endowment; generally, peripheral regions are more abundant in labor endowment than core regions. Moreover, periphery regions in China are abundant in natural resources. Based on resource intensity, the spatial distribution of manufacturing industries across core and periphery regions are hypothesized as follows.

Hypothesis 4: Resource intensive industries tend to develop in regions with abundant resources. Labor-intensive industry will be skewed towards periphery areas with lower labor cost. Energy intensive industries will be skewed towards the periphery with abundant energy resources.

Hypothesis 5: Higher skill intensive industry will be skewed towards core regions.

China is a country in transition, so the impact of a planned economy and local protection on spatial distribution of industries cannot be neglected. Young (2000) studied the relationship between regional protectionism and industrial distribution. Regional protectionism is the result of progressive marketization in China. With the progress of market-oriented reform, several rents emerge from the old system in several departments. To protect these benefits, local governments have set many barriers to hamper commodities moving across regions, weakening specialization. Lu and Tao (2009) found that local protectionism among China's various regions obstructs the process of geographical concentration of manufacturing industries. Regional protectionism is difficult to be quantified, as no evident can measure it either specifically or overall. Therefore, tax-output proportion and state-owned enterprises ratio are applied to indicate protection, as Huang and Li (2006) implement in their research. Moreover, they have captured the evolving effect of market-oriented reforms on industrial distribution by measuring the significance of estimation from multi-periods.

Additionally, industrial location gradually follows regional advantages along with further integration across regions, which would lead to greater proper spatial organization. Taking the EU for example, Cutrini (2010) found national specialization has emerged particularly in the EU founding member states, and there is evidence of an increasing polarization of the north/south divide closely connected with the growing concentration of high-tech sectors.

Hypothesis 6: Industries with higher tax-output proportion and state-owned enterprises ratio tend to be locked in regions with high protectionism.

Hypothesis 7: Spatial disparity between core and periphery would be intensified as China deepens market reform and international trade liberalization.

\subsection{Methods}

\subsubsection{A measure of centrality}

Brülhart (2001) presented a method to measure core-periphery pattern in his study on spatial distribution of industries in the EU. Combes and Overman (2004) also show economic spatial structure in the EU using this method. The principle of the method lies in the use of relative market access to define a core or periphery. Based on the market potential method created by Harris (1954), the market potential of region $r$ is given by the sum of regional GDPs, 
where the GDP of region $s$ is weighted by the inverse of its distance to region $r$. Using these weights, the market potential aims to capture the idea that proximity to prosperous regions makes a region more attractive because it offers good access to several large markets (Combes et al., 2008). Using market potential to find a region's place in the core-periphery pattern is to emphasize that not only the level of development, but also the location could determine the importance of a region. Market access is a key factor while measuring a region's attraction to manufacturers and production factors. A region becomes more attractive if it is closer to a core prosperous area, as this market access allows the products of the region to flow into a larger market easily, and the region becomes more involved in regional specialization and cooperation systems. Thus, this region could be considered a core region. The formula to calculate centrality is

$$
\begin{aligned}
& \text { Centrality }_{c t}=\frac{1}{N}\left[\left(\sum_{d} \frac{\sum_{i} E_{i d}}{\delta_{c d}}\right)+\frac{\sum_{i} E_{i c}}{\delta_{c c}}\right], \quad c \neq d \\
& \delta_{c c}=\frac{2}{3}\left(\text { Area }_{c} / \pi\right)^{1 / 2}
\end{aligned}
$$

where $c$ and $d$ denote regions, $N$ is the number of countries in the sample, and $\delta_{c d}$ stands for geographical distance. This definition takes into account each region's own economic size and area, as well as its distance from other markets (in terms of GDP). Bilateral distance $\delta_{c d}$ is defined as the distance between capital cities. Intra-country distance $\delta_{c c}$ is computed, following Leamer (1997), as one third of the radius of a circle with the same area as the region in question.

\subsubsection{Industrial characteristic bias}

We apply the industrial characteristic bias defined by Midelfart-Knarvik et al. (2000) to measure industrial structure differences for each province, or in what sort of industries provinces are specializing. As we stick to manufacturing industries, this index refers here to a manufacturing industrial characteristic bias.

$$
I C B_{i}=\sum_{k=1}^{n} S_{i k} Z_{j k}
$$

For each characteristic, we define the industrial characteristic bias (ICB) of province $i$, as in equation (3). We compute, for each province, the average score on each characteristic, where each industrial characteristic is weighted by the share of that industry in the country's production. Here, we have a set of industrial characteristics, which are listed in Table 1. ICB refers to industrial characteristic bias, $Z_{j k}$ is the $j$ th characteristic for $k$ industry, $S_{i k}$ is the weight of $k$ industry in whole manufacturing for $i$ region, which is measured by the share of that industry's output in the province's total manufacturing output. It is bigger in province $i$ than others, for each $I C B$ indicates that the province is specialized in that corresponding industry. For example, in terms of energy intensity, a province with high $I C B$ implies that the industrial structure of this province is more energy intensive, and vice versa. ICB is used to reflect the composition deference of manufacturing industries for each province. This means that the influence of disparity of technological level among provinces has to be eliminated. Therefore, the industrial characteristics remain unchanging over time, which are depicted also by data in the 2007 input-output table of China. 
Table 1 Indicators of industrial characteristic

\begin{tabular}{cll}
\hline & \multicolumn{1}{c}{ Industrial characteristic $\left(z_{j}^{k}\right)$} & \multicolumn{1}{c}{ Measurement } \\
\hline$j=1$ & Intermediate input ratio & Intermediate inputs, \% of output \\
$j=2$ & Ultimate consumption ratio & Domestic consumption, \% of total sale ${ }^{1}$ \\
$j=3$ & Scale economy & Employment per enterprise \\
$j=4$ & Labor intensity & Percentage of labor wage in output, \% of output \\
$j=5$ & Higher skills intensity & Share of higher educated workers in workforce \\
$j=6$ & Energy intensity & Energy consumption per output, ton standard coal \\
$j=7$ & Tax rate & Percentage of tax in output, \% of output \\
$j=8$ & State-owned enterprise raito & $\begin{array}{l}\text { Percentage of state-owned enterprise in total enterprise, } \\
\% \text { of total enterprise }\end{array}$ \\
\hline
\end{tabular}

\subsubsection{Location quotient}

The location quotient measures the relative concentration of industry on a nationwide scale. It shows the comparative advantage of one region for an industry, and describes the specialization of this industry in view of spatial features. This measure takes values between zero and infinity, and relates positively to a region's specialization in the particular industry. If the value is greater than 1 , then this region is said to be specialized in this given industry. The greater the value is, higher the level of specialization. It is calculated as follows:

$$
Q_{i c}=\frac{E_{i c}}{\sum_{c} E_{i c}} / \frac{\sum_{i} E_{i c}}{\sum_{i} \sum_{c} E_{i c}}
$$

where $E$ stands for output, and the subscripts $i$, c and $t$ denote industries, provinces, and years, respectively. $E_{i c}$ is scale of industry $i$ in region $c, \sum_{i} E_{i c}$ is scale of all industries in province $c, \sum_{c} E_{i c}$ is scale of industry $i$ in all provinces, and $\sum_{i} \sum_{c} E_{i c}$ is scale of all industries in all provinces.

\subsubsection{Empirical model}

We apply an econometric model to find the relationship of spatial patterns to the coreperiphery gradient and its key influential factors, thereby testing the hypothesis. To resolve for specification issues, we construct a very general simulation model that nests within it both traditional trade theory and new economic geography models. Hence, we adopt a model used by Ellison and Glaeser (1999) and Midelfart-Knarvik et al. (2000) to measure interaction of regional and industrial characteristics. The essence of the model lies in establishing the relationship between industries and regions, or, in analyzing which region is more attractive to a certain industry. The model is presented as follows:

$$
\ln \left(S_{i}^{k}\right)=\alpha \ln \left(\operatorname{man}_{i}\right)+\beta \ln \left(\text { pop }_{i}\right)+\sigma \ln \left(\text { path }_{i}\right)+\tau f d m_{i}+\sum_{j} \gamma_{j}\left(y_{j}^{i}-\theta_{j}\right)\left(z_{j}^{k}-\delta_{j}\right)
$$

where $S_{i}^{k}$ is the share of industry $k$ in region $i$, pop $_{i}$ is the share of the whole country's population living in region $i$, and $\operatorname{man}_{i}$ is the share of the total manufacturing located in re-

\footnotetext{
1 Total sales of industry are calculated by sum of resident consumption, government consumption, and fixed assets.
} 
gion $i$. The new economic geography believes that the historic economy is important to industry growth; hence, $p a t h_{i}$ is added in the model to control for the effect of path dependence, presented by the scale of same industry lagged by 5 years. In an open economy, foreign investment and international trade also have effects on industrial distribution, hence foreign market access $f d m_{i}$ is applied in the model to measure geographical advantage on foreign economic activity for one region, calculated by the inverse distance from a region to the coast; $\alpha, \beta, \sigma, \tau, \gamma_{j}$ are regression coefficients, and $\theta_{j}$ and $\delta_{j}$ are critical levels. When estimating the equation, we need to derive estimates of the three key parameters for each interaction variable, that is, of $\theta_{j}, \delta_{j}$ and $\gamma_{j}$. We also derive estimates for the impact of the two scale variables and the other controlling variables, that is, of $\alpha, \beta, \sigma$, and $\tau$. In the discussion of our results, we concentrate on $\gamma_{j}$ which measures the sensitivity of all industries to variations in regional characteristics. Returning to the example of centrality, if the core-periphery dimension is an important determinant of industrial location, then we should obtain a high value of $\gamma_{j}$. If it equals $\theta_{j}$, there is no preference by the industry to the region; if it is greater than $\theta_{j}$, the industry preferring the core region tends to locate there, and if it is smaller than $\theta_{j}$, the industry preferring the periphery regions tends to locate there. Correspondingly, $\delta_{j}$ measures certain characteristics of the industry, taking scale economy as an example. If it equals $\delta_{j}$, the industry has no preference to any region; if it is smaller than $\delta_{j}$, the industry tends to locate in core regions, and, the industry tends to locate in the periphery if it is greater than $\delta_{j}$. If regional economic gradient determines the change of distribution disparity of industries with different eigenvalues for the scale economy, a high $\gamma_{j}$ is expected, as well as other industrial characteristics. If $\gamma_{j}$ is greater than 0 , the industry with a high eigenvalue tends to locate in the corresponding area, and vice versa.

To emphasize, we have to consider both high and low intensities and high and low abundance as a result of the general equilibrium nature of the system, which makes estimating these relationships very complex (Midelfart-Knarvik et al., 2000). It is also the general equilibrium nature of the system that stops us from guessing the cut-off points for $\theta_{j}$ and $\delta_{j}$. Actually, there is little reason to think that the mean or median are the correct cut-off points, however intuitive these values might be (Midelfart-Knarvik et al., 2000). Finally, after adjusting for industrial and regional characteristics we can directly compare the importance of different regional characteristics by considering the relative sensitivity of all industries to those characteristics as captured through the estimates of $\gamma_{j}$. Thus, $\theta_{j}, \delta_{j}$, and $\gamma_{j}$ will not be estimated directly but considered in the model by expanding the interaction of regional and industrial characteristics, estimating $\gamma_{j},-\gamma_{j} \theta_{j},-\gamma_{j} \delta_{j}$, dividing the estimation of $\gamma_{j} \theta_{j}$ by $\gamma_{j}$. Similarly, industrial characteristic $\delta_{j}$ can be estimated. If the model is correct, the estimations of $\theta_{j}$ and $\delta_{j}$ are positive. If the estimation of $\gamma_{j}$ appears in contradiction to $-\gamma_{j} \theta_{j},-\gamma_{j} \delta_{j}$, then the revised model is as follows:

$$
\begin{aligned}
\ln \left(S_{i}^{k}\right)= & \mu+\alpha \ln \left(\text { man }_{i}\right)+\beta \ln \left(\text { pop }_{i}\right)+\sigma \ln \left(\text { path }_{i}\right)+\tau f d m_{i} \\
& +\left(\gamma_{j} y_{j}^{i} z_{j}^{k}-\gamma_{j} \theta_{j} z_{j}^{k}-\gamma_{j} \delta_{j} y_{j}^{i}\right)
\end{aligned}
$$

Table 2 shows the method to measure industrial characteristics. Regional centrality is measured by the centrality indicator. Labor endowment is measured by GDP per capita, owing to lack of reliable wage statistics. Generally, income per capita is higher in the region 
with high GDP per capita and labor cost. Energy endowment is measured by energy-output data of the corresponding province instead of the prefecture, as prefecture level data is hard to obtain. Generally, if a province is an energy abundant region, its prefecture is energy abundant as well. The level of protectionism is measured by the proportion of fiscal revenue in GDP for a given prefecture.

Table 2 Definition of independent variables

\begin{tabular}{llll}
\hline & \multicolumn{1}{c}{ Regional characteristic $\left(y_{j}^{i}\right)$} & \multicolumn{1}{c}{ Industrial characteristic $\left(z_{j}^{k}\right)$} & Hypothesis \\
\hline$j=1$ & Centrality (Centrality) & Intermediate input ratio (Input) & Hypothesis 1 \\
$j=2$ & Centrality (Centrality) & Ultimate consumption ratio (Dmnd) & Hypothesis 2 \\
$j=3$ & Centrality (Centrality) & Scale economy (Scale) & Hypothesis 3 \\
$j=4$ & Labor endowment (L-endmnt) & Labor intensity (L-inten) & Hypothesis 4 \\
$j=5$ & High skills- endowment (H-endmnt) & Higher skills intensity (H-inten) & Hypothesis 5 \\
$j=6$ & Energy endowment (Eng-endmnt) & Energy intensity (Eng-inten) & Hypothesis 5 \\
$j=7$ & Local protection (Local) & Tax rate (Tax) & Hypothesis 6 \\
$j=8$ & Local protection (Local) & State-owned enterprise raito (State) & Hypothesis 6 \\
\hline
\end{tabular}

Note: Letters in parentheses refer to regional and industrial characteristics.

\subsection{Data sources}

This paper identifies spatial distribution of manufacturing industries in China in the years 1980, 1985, 1995, 2004, and 2008. Data used in the empirical test pertains only to 1985, 1995, 2004, and 2008. Data pertaining to 1980, 1985, and 1995 refer to the first and second industrial census, respectively, and data pertaining to 2004 and 2008 refers to the first and the second economic census, respectively, which are conducted by National Bureau of Statistics (NBS) in China. This dataset contains all state-owned enterprises (SOEs) and non-state- owned enterprises. All input and output data for industries is from the 2007 Input-Output Table of China, while energy data is drawn from the China Energy Statistical Yearbook. Regional GDP (in constant prices in 2001), population, public finance, tax, and area are from the China Statistical Yearbook for the regional economy. Highway mileage among regions is drawn from the electronic edition of China Traffic Maps, which have helped reveal the geography of communication by using highway mileage instead of straight-line distance.

The paper only discusses the segmented industry of manufacturing, excluding mining and public utilities industries such as logging, power, and gas, because of the latter relying highly on local natural resources or local demand. Government regulated industries, such as tobacco processing, are also excluded as they are not classified as footloose. The paper includes 27 sub-industries of manufacturing, according to the industrial classification of industrial census and the economic census, using double-digit industry caliber.

The geographical unit of analysis is province-level area. This paper only studies the situation of mainland China, while Hong Kong, Macau, and Taiwan are not included. During 1980 to 2008, the only change of administrative division at province level in China was the separation of Hainan from Guangdong in 1988, and Chongqing from Sichuan to become a 
municipality city in 1997. According to statistics, the number of geographical units was 29 before 1988, 30 from 1988 to 1997, and 31 after 1997.

\section{Results}

\subsection{Core-periphery pattern in China}

Figure 1 depicts centrality for all provinces in 2008, which reveals a very strong coreperiphery structure in China. Geographical distribution of economic activities is skewed towards East China, specifically coastal regions. As the distance to the core regions increases, centrality steadily decreases from east to west and from coast to inland. Some regions in the Northwest, Northeast, and Southwest China are most peripheral. In fact, this spatial structure is the result of the main economic center moving towards Southeast China since the Tang and Song dynasties. Moreover, compared to that of 1980 (Figure 2), the polarization of economic development in East China has intensified. Figure 2 shows variation of centrality for each province from 1980-2008. The east-coastal regions are seen to have a higher growth rate of centrality, especially Guangdong, Zhejiang, Fujian, and others, whereas the central

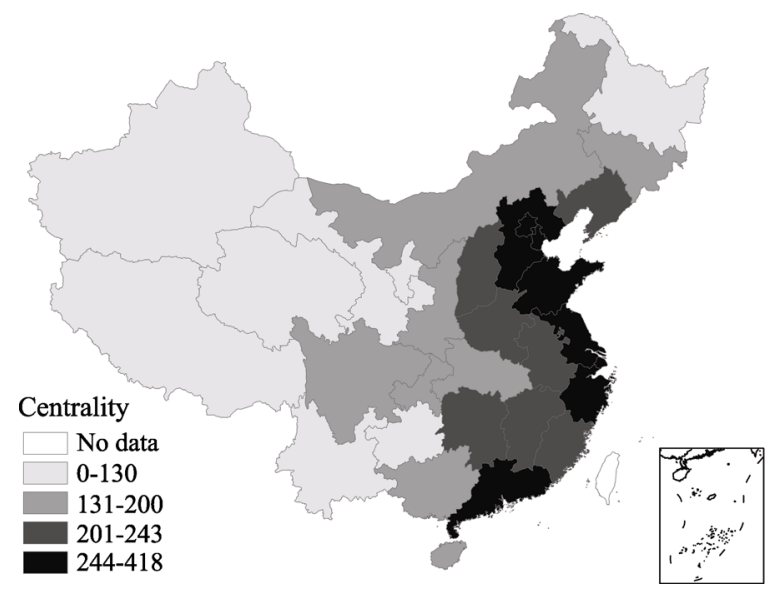

Figure 1 Centrality of GDP in the Provinces of China in 2008

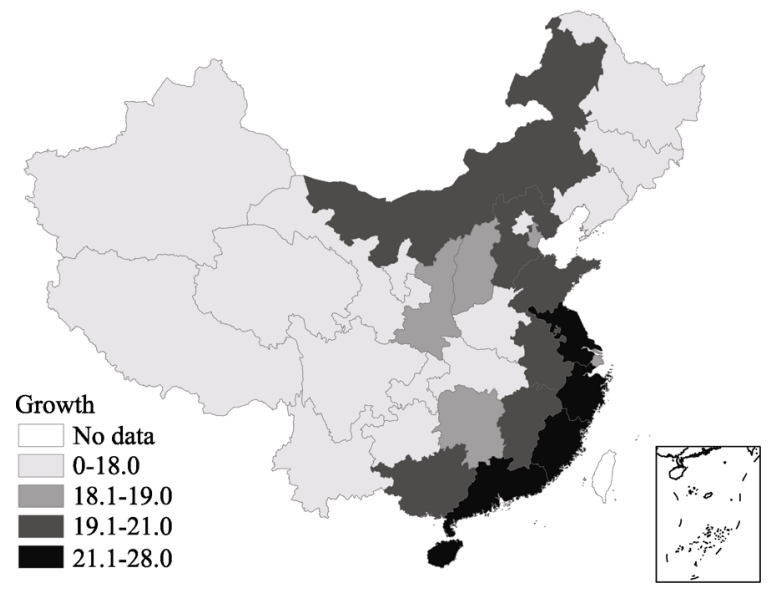

Figure 2 Variation of centrality of GDP in the provinces of China (1980-2008) 
and western regions, as well as some pre-reform traditional industrial bases failed to quickly increase centrality. This indicates that most provinces located in East China, especially coastal provinces, have been more successful than the central and western regions in improving their centrality. The gravity of the economy in China has been gradually skewed southeastwards.

\subsection{Core-periphery gradients of manufacturing}

To analyze the core-periphery gradients of manufacturing for specific industry, we calculate Pearson correlations between regional centrality and the national location quotient of each industry produces a simple statistic that captures the degree to which an industry's geographical distribution is skewed towards the central regions (if the correlation is positive) or towards the periphery (if the correlation is negative). The results listed in Table 3 show that a majority of sectors present statistically significant core-periphery gradients since 1980, which indicates increasing specialization between core and periphery regions.

Table 3 shows that the Pearson correlation of only three industries is always significantly positive from 1980 to 2008, that is (a) stationery, educational and sports goods, (b) metal products, and (c) electronic and telecommunications. Besides, the correlation of electrical equipment and machinery is also significantly positive throughout, except for 1995. It indicates that those industries are skewed towards regions with higher centrality. By further looking at the dynamic of the correlation, we find that the correlation of stationery and educational and sports goods has been decreasing, whereas that of metal products and electronic and telecommunications has shown an increasing trend in correlation. This indicates that stationery, educational, and sports goods are less related to core provinces, while metal products and electronic and telecommunications are more related to them.

The Pearson correlation of nonmetal mineral products and food processing are significantly positive. If we treat food producing in 1980 and 1985 similar to food processing (considering food producing to include food processing before statistic standard adjustment), the correlation of food processing is always significantly negative, like nonmetal mineral products, indicating that nonmetal mineral products and food processing are clearly skewed to peripheral provinces.

After studying two kinds of industries that reveal increasing significance, we turn to look at industries with dynamic significance over time. Garments and other fiber products have positive correlation throughout; however, the value appears to decrease and become insignificant, which means these industries are less related to core regions and show trends in transferring to periphery areas. Machinery, equipment and instruments, meters, and cultural and official machinery show the contrary, with the correlation significantly positive and the value increasing over time, implying that those industries are inclined to concentrate towards core regions with stronger trends. Food producing shows a negative correlation, but the significance has been weakening, besides, the absolute value tends towards a decrease, all this evidence revealing the pattern of peripheral provinces specializing in this industry to have weakened, to a certain degree indicating a trend of shift to core provinces.

The correlation of raw chemical materials and chemical products, and smelting and pressing of ferrous metals, shifts to a negative correlation from positive in 1995 and 2004. Although neither of them is significant, we can still propose those two industries to have 
Table 3 Correlation coefficients between location quotient and centrality index (1980-2008)

\begin{tabular}{|c|c|c|c|c|c|}
\hline Sector & 1980 & 1985 & 1995 & 2004 & 2008 \\
\hline Food processing & - & - & $-0.4105^{* *}$ & $-0.2229^{*}$ & $-0.3899^{* *}$ \\
\hline Food production & $-0.5044^{* * *}$ & $-0.5248^{* * *}$ & -0.0590 & -0.1254 & -0.2046 \\
\hline Beverage production & -0.2515 & $-0.3488^{*}$ & -0.2516 & -0.2970 & -0.2676 \\
\hline Tabaco processing & -0.1824 & -0.2025 & -0.2215 & -0.1815 & -0.1810 \\
\hline Feed manufacturing & $0.4954^{* * *}$ & 0.0718 & - & - & - \\
\hline Textile industry & 0.2534 & 0.2205 & -0.0122 & 0.0159 & 0.0007 \\
\hline Garments \& other fiber products & - & - & $0.4604^{* *}$ & $0.3243^{*}$ & 0.2247 \\
\hline Leather, furs, down \& related products & -0.1927 & -0.1982 & -0.0908 & 0.0447 & -0.0144 \\
\hline $\begin{array}{l}\text { Timber processing, bamboo, cane, palm fiber } \\
\& \text { straw products }\end{array}$ & -0.1036 & -0.1291 & -0.1991 & -0.1769 & $-0.2915^{*}$ \\
\hline Furniture manufacturing & $-0.3285^{* *}$ & -0.2417 & -0.1485 & 0.2593 & 0.2409 \\
\hline Papermaking \& paper products & -0.1241 & -0.1557 & -0.2946 & -0.0999 & -0.0863 \\
\hline Printing \& record pressing & -0.2045 & -0.1197 & -0.2138 & -0.0184 & -0.0246 \\
\hline Stationery, educational \& sports goods & $0.8618^{* * *}$ & $0.7963^{* * *}$ & $0.4633^{* * *}$ & $0.4412^{* *}$ & $0.3442^{*}$ \\
\hline Petroleum processing & -0.0587 & -0.1353 & - & - & - \\
\hline Coking products, \& gas production $\&$ supply & $0.4626^{* *}$ & $0.4010^{* *}$ & - & - & - \\
\hline $\begin{array}{l}\text { Petroleum processing, } \\
\text { Coking products, \& gas production \& supply }\end{array}$ & - & - & -0.0575 & -0.1457 & -0.1552 \\
\hline Raw chemical materials \& chemical products & 0.1798 & 0.2416 & -0.0781 & -0.1218 & -0.1950 \\
\hline Medical \& pharmaceutical products & 0.1947 & 0.0521 & -0.0628 & -0.2211 & -0.2216 \\
\hline Chemical fibers & $0.7643^{* * *}$ & $0.7979^{* * *}$ & $0.3251^{*}$ & 0.0504 & 0.0064 \\
\hline Rubber products & 0.0232 & 0.0796 & -0.0312 & 0.0664 & 0.0776 \\
\hline Plastic products & 0.1082 & 0.1829 & 0.0462 & 0.2367 & 0.2562 \\
\hline Nonmetal mineral products & $-0.5341^{* * *}$ & $-0.5941^{* * *}$ & $-0.4634^{* * *}$ & $-0.2413^{*}$ & $-0.3005^{*}$ \\
\hline Smelting \& pressing of ferrous metals & 0.1792 & 0.1601 & 0.1648 & -0.0363 & -0.0167 \\
\hline Smelting \& pressing of nonferrous metals & -0.0692 & -0.0783 & -0.2389 & -0.2733 & -0.2877 \\
\hline Metal products & $0.3268^{*}$ & $0.4091^{* *}$ & $0.3639^{* *}$ & $0.5611^{* * *}$ & $0.5404^{* * *}$ \\
\hline Machinery manufacturing & 0.0873 & 0.0730 & - & - & - \\
\hline Machinery \& equipment manufacturing & - & - & 0.2073 & $0.4077^{* *}$ & $0.4740^{* * *}$ \\
\hline Special equipment manufacturing & - & - & 0.0235 & 0.1615 & 0.2795 \\
\hline Transportation equipment manufacturing & -0.1849 & -0.1822 & 0.1512 & 0.0274 & 0.1411 \\
\hline Electric equipment \& machinery & $0.3733^{* *}$ & 0.2818 & $0.3335^{*}$ & $0.3674^{* *}$ & $0.3403^{*}$ \\
\hline Electronic \& telecommunications & $0.5434^{* * *}$ & $0.3652^{* *}$ & $0.4736^{* * *}$ & $0.6469^{* * *}$ & $0.7024^{* * *}$ \\
\hline $\begin{array}{l}\text { Instruments, meters, } \\
\text { cultural \& official machinery }\end{array}$ & 0.2826 & 0.2894 & $0.5641^{* * *}$ & $0.4860^{* * *}$ & $0.5477^{* * *}$ \\
\hline
\end{tabular}

Note: $*=$ significant at $5 \%$ level; $* *=$ significant at $10 \%$. To simply page allocation, standard errors haven't been reported. "-" refers no data.

skewed towards the periphery instead of the core provinces. In contrast, the correlation of furniture manufacturing and transportation equipment manufacturing changes to positive from negative, but remains insignificant. Nevertheless, we are able to say that those two industries have been skewed towards core provinces instead of the periphery. 
In summary, according to the names of sectors, industries that are inclined towards core provinces are relatively more reliant on high skills, a better development base, and market access, while industries inclined to the periphery are more reliant on energy, labor, and natural resources.

\subsection{Empirical analysis of core-periphery pattern and regional specialization}

The model could suffer from an inherent endogeneity problem. As Hanson (2001) argued, when regressing regional productivity on a measure of regional agglomeration, one is forced to take into account the possibility that causality runs from the former to the latter. First of all, the dependent variable might affect independent variables, especially regional feature. For example, regions with a high industry proportion have a high industrial base as well, with both factors possibly affected by other factors. Secondly, the industrial feature might affect regional feature, for example, scale-economic industries prefer to locate in regions with a better industrial base. However, the choice of those industries will also promote industrial agglomeration in the region. As with circular causation explained by the new economic geography, industry tends to cluster in core regions with high industrial base, also strengthening the centrality of the region.

OLS cannot be applied here owing to endogeneity. The instrument to be introduced is methodological, in order to solve this problem and increase the robustness of regression, which should satisfy two conditions: (1) it must be relevant to the explained variable, and (2) it must be irrelevant to the error term. To this model, the instrument should be relevant to regional characteristics but not to industrial characteristics to control the effect of the choice of industry on regional characteristic. This paper uses a five-year lagged regional characteristic variable as the instrument, referring to Huang and Li (2006). Under the Hausman test and over identifying test, this variable proved to be valid.

Industrial development is uneven among regions in China since reforms and opening-up. The paper applies the White test to deal with heteroscedasticity. Comparatively speaking, considering the co-efficient of regional characteristics and industrial characteristics individually does not make much sense. The key lies in $\gamma_{j}$ of interaction variables and its significance. Thus in Table 4, there exist only the estimated coefficients of interaction variables of regional characteristics and industrial characteristics, and other control variables. Correspondingly, Table 5 shows the results of the two stage least squares (2SLS), with the instrument. The coefficient is as robust as expected, except that the significance of L-endmnt $\times$ $L$-inten has not sustained, and that $H c$-endmnt $\times H c$-inten has changed to negative from positive (without significance) in the estimation for 1985. The general conclusion of this paper, however, does not change. In next section, we analyze the estimation of model based by results of 2SLS.

Generally speaking, variables Man and Pop measure the effect of regional scale on industrial distribution. The coefficient of Man is significantly positive in the estimations of all four terms, which shows that if manufacturing is large in one province, each sub-industry is large too. However, the coefficient and its significance are decreasing, which means the specialization has been deepening. The coefficient of Pop is insignificantly positive in 1985 and significantly positive since 1995 , which means that the impact of the central government's plan on industrial location has weakened and industrial distribution has gradually increased in relevance to the population distribution. Besides, the result of the regression demonstrates 
the effect of international factors as significant to the spatial distribution of industries. Further, while local protection has had considerable effect on industrial distribution, the impact has been weaker, according to the dynamic of the coefficient over time, as trade liberalization and market oriented reform has reduced the influence of domestic market on economic growth. While foreign trade has promoted the economy to a greater extent, local government has had fewer motives to implement local protection. Besides the variables mentioned above, the coefficient of Path is significantly positive in all regressions, which shows that path dependence has had important effects on industrial location.

Table 4 Results of the least square estimation

\begin{tabular}{|c|c|c|c|c|}
\hline & 1985 & 1995 & 2004 & 2008 \\
\hline \multicolumn{5}{|l|}{ Interactions } \\
\hline Centrality $\times$ Input & $\begin{array}{c}0.1434 \\
(0.0881)\end{array}$ & $\begin{array}{l}0.1024^{* * *} \\
(0.0243)\end{array}$ & $\begin{array}{c}0.0446^{* * *} \\
(0.0118)\end{array}$ & $\begin{array}{l}0.0269^{* * *} \\
(0.0076)\end{array}$ \\
\hline Centrality $\times$ Dmnd & $\begin{array}{c}0.0292 \\
(0.0268)\end{array}$ & $\begin{array}{l}0.0309^{* * *} \\
(0.0071)\end{array}$ & $\begin{array}{c}0.0160^{* * *} \\
(0.0034)\end{array}$ & $\begin{array}{l}0.0101^{* * *} \\
(0.0022)\end{array}$ \\
\hline Centrality $\times$ Scale & $\begin{array}{l}0.0201^{* * *} \\
(0.0074)\end{array}$ & $\begin{array}{l}-0.0021 \\
(0.0030)\end{array}$ & $\begin{array}{c}0.0010^{*} \\
(0.0015)\end{array}$ & $\begin{array}{c}0.0019^{*} \\
(0.0028)\end{array}$ \\
\hline L-endmnt $\times$ L-inten & $\begin{array}{l}-0.0001 \\
(0.0034)\end{array}$ & $\begin{array}{c}0.0001^{*} \\
(0.0000)\end{array}$ & $\begin{array}{l}-0.0001 \\
(0.0000)\end{array}$ & $\begin{array}{c}0.0001 \\
(0.0000)\end{array}$ \\
\hline Hc-endmnt $\times H c$-inten & $\begin{array}{l}-0.0016 \\
(0.0049)\end{array}$ & $\begin{array}{l}-0.0006 \\
(0.0008)\end{array}$ & $\begin{array}{c}-0.0007^{*} \\
(0.0004)\end{array}$ & $\begin{array}{l}-0.0002 \\
(0.0002)\end{array}$ \\
\hline Eng-endmnt $\times$ Eng-inten & $\begin{array}{c}0.0717 \\
(0.0500)\end{array}$ & $\begin{array}{l}0.0778^{* * *} \\
(0.0301)\end{array}$ & $\begin{array}{c}0.0849^{* * *} \\
(0.0264)\end{array}$ & $\begin{array}{c}0.0582^{* * *} \\
(0.0187)\end{array}$ \\
\hline \multicolumn{5}{|l|}{ Other variables } \\
\hline Мапи & $\begin{array}{l}0.8834^{* * *} \\
(0.1208)\end{array}$ & $\begin{array}{l}0.7545^{* * *} \\
(0.0957)\end{array}$ & $\begin{array}{c}0.6721^{* * *} \\
(0.1247)\end{array}$ & $\begin{array}{l}0.5921^{* * *} \\
(0.1325)\end{array}$ \\
\hline Pop & $\begin{array}{c}0.1633 \\
(0.1596)\end{array}$ & $\begin{array}{l}0.3467^{* *} \\
(0.1258)\end{array}$ & $\begin{array}{c}0.4683^{* * *} \\
(0.1539)\end{array}$ & $\begin{array}{c}0.5977^{* * *} \\
(0.1670)\end{array}$ \\
\hline$F d m$ & $\begin{array}{l}-0.0550 \\
(0.1084)\end{array}$ & $\begin{array}{c}0.0030^{*} \\
(0.0691)\end{array}$ & $\begin{array}{c}0.1558^{*} \\
(0.0898)\end{array}$ & $\begin{array}{l}0.1879^{* *} \\
(0.0933)\end{array}$ \\
\hline Path & $\begin{array}{c}0.8939^{* * *} \\
(0.0127)\end{array}$ & $\begin{array}{l}0.9083^{* * *} \\
(0.0207)\end{array}$ & $\begin{array}{l}1.0111^{* * *} \\
(0.0285)\end{array}$ & $\begin{array}{c}0.9258^{* * *} \\
(0.0177)\end{array}$ \\
\hline Local $\times$ Tax & $\begin{array}{c}22.6602 \\
(15.6260)\end{array}$ & $\begin{array}{c}19.7197 \\
(10.7284)\end{array}$ & $\begin{array}{c}2.4767 \\
(2.7029)\end{array}$ & $\begin{array}{c}1.4283 \\
(1.3357)\end{array}$ \\
\hline Local $\times$ State & $\begin{array}{c}56.1146^{*} \\
(36.8005)\end{array}$ & $\begin{array}{l}35.7379^{* *} \\
(26.6363)\end{array}$ & $\begin{array}{c}27.3633^{*} \\
(16.6759)\end{array}$ & $\begin{array}{c}2.7619 \\
(3.3154)\end{array}$ \\
\hline Adjusted R-squared & 0.8466 & 0.8614 & 0.8840 & 0.8295 \\
\hline S.E. & 0.653 & 0.721 & 0.701 & 0.692 \\
\hline Number of obs & 765 & 826 & 866 & 872 \\
\hline
\end{tabular}

Note: Standard errors reported in brackets; $*=$ significant at $5 \%$ level; $* *=$ significant at $10 \%$. S.E. refers standard errors. All regressions are overall significant according to the standard F-test.

According to variations in the coefficient of interaction variables of regional and industrial characteristics, industrial distribution is in line with what theory mostly expects. Industrial location is based on regional development advantage, and the distribution is as reasonable as theory predicted. In other words, regional advantage (regardless of first nature and 
Table 5 Results of estimation by two stages least square

\begin{tabular}{|c|c|c|c|c|}
\hline & 1985 & 1995 & 2004 & 2008 \\
\hline \multicolumn{5}{|l|}{ Interactions } \\
\hline Centrality $\times$ Input & $\begin{array}{l}-0.1499 \\
(0.3638)\end{array}$ & $\begin{array}{l}0.1727^{* *} \\
(0.0448)\end{array}$ & $\begin{array}{l}0.0483^{* * *} \\
(0.0133)\end{array}$ & $\begin{array}{l}0.0277^{* * *} \\
(0.0077)\end{array}$ \\
\hline Centrality $\times$ Dmnd & $\begin{array}{l}-0.0013 \\
(0.0403)\end{array}$ & $\begin{array}{l}0.0337^{* *} \\
(0.0078)\end{array}$ & $\begin{array}{c}0.0155^{* * *} \\
(0.0034)\end{array}$ & $\begin{array}{l}0.0102^{* * *} \\
(0.0021)\end{array}$ \\
\hline Centrality $\times$ Scale & $\begin{array}{l}0.0314^{* * *} \\
(0.0098)\end{array}$ & $\begin{array}{c}0.0097 \\
(0.0076)\end{array}$ & $\begin{array}{l}0.0146^{* *} \\
(0.0056)\end{array}$ & $\begin{array}{l}0.0071^{* *} \\
(0.0038)\end{array}$ \\
\hline L-endmnt $\times$ L-inten & $\begin{array}{l}-0.0034 \\
(0.0061)\end{array}$ & $\begin{array}{l}-0.0001 \\
(0.0001)\end{array}$ & $\begin{array}{c}-0.0002^{* *} \\
(0.0001)\end{array}$ & $\begin{array}{l}-0.0001^{* *} \\
(0.00003)\end{array}$ \\
\hline$H c$-endmnt $\times H c$-inten & $\begin{array}{c}0.0015 \\
(0.0055)\end{array}$ & $\begin{array}{c}0.0009 \\
(0.0010)\end{array}$ & $\begin{array}{c}0.0011^{*} \\
(0.0007)\end{array}$ & $\begin{array}{l}0.0051^{* *} \\
(0.0002)\end{array}$ \\
\hline Eng-endmnt $\times$ Eng-inten & $\begin{array}{c}0.0850 \\
(0.0522)\end{array}$ & $\begin{array}{l}0.0787^{* *} \\
(0.0318)\end{array}$ & $\begin{array}{l}0.0880^{* * *} \\
(0.0292)\end{array}$ & $\begin{array}{l}0.0536^{* * *} \\
(0.0200)\end{array}$ \\
\hline \multicolumn{5}{|l|}{ Other variables } \\
\hline Man & $\begin{array}{c}0.8982^{* * *} \\
(0.1201)\end{array}$ & $\begin{array}{l}0.7701^{* * *} \\
(0.0973)\end{array}$ & $\begin{array}{l}0.6702^{* * *} \\
(0.1231)\end{array}$ & $\begin{array}{l}0.6284^{* * *} \\
(0.1298)\end{array}$ \\
\hline Pop & $\begin{array}{c}0.1492 \\
(0.1586)\end{array}$ & $\begin{array}{l}0.3331^{* * *} \\
(0.1276)\end{array}$ & $\begin{array}{c}0.4692^{* * *} \\
(0.1519)\end{array}$ & $\begin{array}{l}0.5818^{* * *} \\
(0.1649)\end{array}$ \\
\hline$F d m$ & $\begin{array}{l}-0.0560 \\
(0.1076)\end{array}$ & $\begin{array}{l}0.0027^{* *} \\
(0.0700)\end{array}$ & $\begin{array}{l}0.156^{* * *} \\
(0.0887)\end{array}$ & $\begin{array}{l}0.1881^{* *} \\
(0.0411)\end{array}$ \\
\hline Path & $\begin{array}{l}0.8989^{* * *} \\
(0.0134)\end{array}$ & $\begin{array}{l}0.9183^{* * *} \\
(0.0231)\end{array}$ & $\begin{array}{l}1.0435^{* * *} \\
(0.0334)\end{array}$ & $\begin{array}{l}0.9239^{* * *} \\
(0.0176)\end{array}$ \\
\hline Local $\times$ Tax & $\begin{array}{c}-7.8106 \\
(26.3684)\end{array}$ & $\begin{array}{c}9.0357 \\
(6.7800)\end{array}$ & $\begin{array}{c}0.3379 \\
(2.9996)\end{array}$ & $\begin{array}{c}1.4541 \\
(1.3498)\end{array}$ \\
\hline Local $\times$ State & $\begin{array}{l}43.0539^{* *} \\
(44.0992)\end{array}$ & $\begin{array}{l}37.4653^{* *} \\
(28.7800)\end{array}$ & $\begin{array}{l}17.7382^{*} \\
(9.3935)\end{array}$ & $\begin{array}{c}2.6360^{*} \\
(3.4418)\end{array}$ \\
\hline Adjusted R-squared & 0.8411 & 0.8573 & 0.8278 & 0.8264 \\
\hline S.E. & 0.639 & 0.711 & 0.693 & 0.671 \\
\hline Number of obs & 765 & 826 & 866 & 872 \\
\hline
\end{tabular}

Note: Standard errors reported in brackets; $*=$ significant at $5 \%$ level; $* *=$ significant at $10 \%$. S.E. refers to standard errors. All regressions are overall significant according to the standard F-test.

second nature) plays an important role in the industrial distribution. Some provinces as important industrial bases have been in decline, and instead, some coastal provinces have been emerging. In the estimation results of 1985 , only the efficient of Centrality $\times$ Scale is significant, moreover, many coefficients have not been consistent with theoretical expectations. In 2 SLS results, the coefficients of Centrality $\times$ Link, Centrality $\times$ Dmnd and L-endmnt $\times$ L-inten are negative, which implies the spatial distribution of manufacturing industries, influenced by a historical planned economy, was not optimal in the early reform and opening-up phases. More coefficients show increases in significance in 1995, such as the coefficients of Centrality $\times$ Link, Centrality $\times$ Dmnd and Eng-endmnt $\times$ Eng-inten, which are significantly positive. Most coefficients accord with our theoretical predictions, except for L-endmnt $\times L$-inten. In the global view, China is a country with abundant labor endowment in international production networks, so labor intensive industries located in coastal regions where wage is higher 
than inland is practical. All coefficients are significant in 2004 and 2008; moreover, Hc-endmnt $\times$ HC-inten has higher significance in 2008 than that in 2004 .

In view of the new economic geography, three pairs of variables are considered in the model: input-output linkage, scale economy, and ultimate consumption. Results show that certain predictions of new economic geography are indeed confirmed by the model.

The coefficient of Centrality $\times$ Input is positive, and has been very significant, indicating that input-output linkage is one of the key factors to industrial location. The intermediate-input intensive industry is more inclined to locate in core provinces. The 1980s saw the beginning of urban reform and state-owned firms, when a planned economy still played an important role in production. Along with the promotion of opening-up and market-oriented reforms since the 1990s, input-output linkages have become increasingly important to production, and has led industries to properly distribute across provinces in line with regional advantages.

The coefficient of Centrality $\times$ Dmnd is also significantly positive, and has been increasingly significant. The impact of the domestic consumption market on the location of ultimate consumption intensive industries is not significant in the 1985 regression; the estimation shows results strongly opposite to our expectations. However, the coefficient turns to be positive and its significance also appears to gradually increase in all regressions since 1990, which indicates that the domestic market was not the determining factor of industrial location, but along with deeper opening-up and market-oriented reform, market potential has been a key factor to industrial location. This has led the ultimate consumption driven industry to locate in core provinces characterized by relatively huge market potential, since market-oriented reform.

The coefficient of Centrality $\times$ Scale changes greatly over time. The coefficient in the 1985 regression is significantly positive, but is not significantly positive in the 1990 regression, and becomes significantly positive again in the regression of 2004 and 2008. These changes imply inclination to core provinces in recent years for industries with scale economy. During the economic transition in early reform and opening-up periods, it is the private enterprises and township enterprises that promoted economic growth, while some provinces of the traditional industrial base lagged in the development of a nonpublic economy. Those that remained state-owned enterprises were normally large scale compared to nonpublic ones, so the scale economy has not always been significant in core provinces with more rapid economic growth. Currently, along with the substantial completion of state-owned enterprise reform and development of nonpublic economy, core provinces have gradually indicated characteristic of a scale economy.

In the view of comparative advantage, three sets of variables are considered in the model: labor intensity, high skill intensity, and energy intensity. Results show that traditional trade theory can also explain industrial spatial distribution to a certain degree.

The coefficient of $L$-endmnt $\times L$-inten is negative, which is not consistent with our theoretical prediction. The coefficient is insignificant in 1985 and 1995, and is significantly negative in 2004 and 2008. It indicates that industrial distribution is not in line with labor endowment across provinces; in contrast, labor-intensive industries are highly concentrated in the relatively high wage region of east-coastal China since the $21^{\text {st }}$ century. It seems to violate principles of comparative advantage; nevertheless, it is not strange if we consider it 
in global view. China is a country with abundant labor endowment; hence, labor-intensive industries located in coastal regions are convenient to international trade emerge as an optimal choice.

The coefficient of Hc-endmnt $\times H c$-inten is not significant in 1985 and 1995 but significantly positive in 2004 and 2008. It implies that human capital was playing an important role in industrial development along with reforms in employment institutions. In the context of concentration of high skilled labor in core provinces, technology intensive industries relying on human capital accumulation has been gradually skewed to core regions.

The coefficient of Eng-endmnt $\times$ Eng-inten is not significant in 1985 but is significantly positive in 1995, 2004, and 2008. Moreover, significance increased to a certain degree after 1995. At first, it may indicate that energy endowment did not determine industrial distribution, but with the deepening of the market-oriented reform, it can be seen that energy-intensive industry is being inclined to locate in energy abundant provinces. Regional development is not too relevant to energy distribution in China, as energy is scarce in core regions while abundant in peripheral regions. Thus, the results of the regression show that the energy-intensive industry is inclined to locate in the periphery, and industrial structure in the periphery has evolved to be higher energy consuming.

\section{Conclusions}

The paper discusses the spatial distribution of manufacturing industries and influencing factors in the view of the core-periphery pattern in China. For long, differences in development among regions have been enlarging, leading to a typical core-periphery pattern emerging. East China, especially coastal areas, have emerged as the core region, and centrality has been declining from east to west and from coast to inland; while Northwest, Southwest and Northeast China have become relatively peripheral. The paper also shows that both traditional trade theory and the new economic geography could explain industrial location in China to a certain extent. In general, along with opening-up and market-oriented reforms, industrial distribution follows own advantages of regions, while regional specialization shows a statistically significant relationship to the core-periphery pattern.

Input-output linkages and market potential are becoming key impact factors to industrial location, which lead intermediate-input intensive industry and ultimate consumption driven industry to cluster in core provinces. Moreover, scale-intensive industry is inclined to locate in core regions as well. Driven by international trade, labor-intensive industry is skewed to core provinces that conveniently allow access to the foreign market. Human capital has played important role in influencing industrial location. In the context of concentration of high skilled labor in the core provinces, the technology intensive industries that rely on human capital accumulation have gradually moved to core regions. Besides, energy intensive industries are relocating to the periphery with abundant energy resource; meanwhile, the industrial structure of the core regions is becoming less energy intensive.

The paper measures regional centrality using relative market access. It shows that the role of a region in core-periphery pattern is not only related to its economic scale or development level, but also its location. East China gained an advantage in the initial stages of opening-up owing to its easy access to the international market. It became the core under the effect of local and international markets. The local market is small in West China, and is far 
away from core regions because of which it is hard to benefit from the national market. Moreover, it can also hardly benefit from the global market because of its location. Hence, the difference between East China and West China is irreversible and it is not easy to shorten the development gap. Uneven development of manufacturing industries in regions has been a trend for long. Within a certain period, a region has to develop a certain industry according to its own advantage and development level. Regional differences in industrial structure then become natural. The core-periphery pattern in China shown in the paper indicates a development disparity between East China and West China, reflecting not only current spatial distribution but also future evolution of industrial structure.

It is important to realize the fact that China is a developing country with huge uneven regional development. Our policies should follow basic economic principles. Practically, regions should develop proper industries based on their own advantages, and not aim to move "upscale" too fast. East China as a core region has been able to upgrade industry at first, while the west may have to develop low-end industry and undertake industries transferred from the east. Regional policies ought to consider livelihoods issue first, and provide public services equally across regions; secondly, a good policy should encourage specialization among regions and avoid cutthroat competition to allocate to China's limited resource or maximum effectiveness.

Owing to the limitation of data, the paper only analyzes 2-digit manufacturing industries. Regional specialization in the 2-digit industry could be significantly different from that in its sub-industries. Regions might be specialized to different sub-industries in same minor industrial category. The specialization difference in regions might be missing if only considering the minor industrial category. Therefore, a modified method to study spatial patterns of economic activities is to use more specific industries.

\section{References}

Bao C, Chen Z, Wu J, 2012. Chinese manufacturing on the move: Factor supply or market access? China Economic Review, 26: 170-181.

Bottazzi G, Dosi G, Fagiolo G et al., 2008. Sectoral and geographical specificities in the spatial structure of economic activities. Structural Change and Economic Dynamics, 19(3): 189-202.

Brülhart M, 2001. Evolving geographical concentration of European manufacturing industries. Weltwirtschaftliches Archiv, 137(2): 215-243.

Brülhart M, Traeger R, 2005. An account of geographic concentration patterns in Europe. Regional Science and Urban Economics, 35(6): 597-624.

Combes P P, Lafourcade M, 2011. Competition, market access and economic geography: Structural estimation and predictions for France. Regional Science and Urban Economics, 41: 508-524.

Combes P P, Mayer T, Thisse J F, 2008. Economic Geography: The Integration of Regions and Nations. Princeton: Princeton University Press.

Combes P P, Overman H G, 2004. The spatial distribution of economic activities in the European Union. Handbook of Regional and Urban Economics, 4: 2845-2909.

Cutrini E, 2010. Specialization and concentration from a twofold geographical perspective: Evidence from Europe. Regional Studies, 44(3): 315-336.

Ellison G, Glaeser E L, 1999. The geographic concentration of industry: Does natural advantage explain agglomeration? The American Economic Review, 89(2): 311-316.

Feng G F, Liu Z Y, Jiang W D, 2010. An analysis on the trends, features and causes of industrial transfer among China's eastern, central and western regions. Modern Economic Science, 32(2): 1-10. (in Chinese) 
Fujita M, Hu D P, 2001. Regional disparity in China 1985-1994: The effects of globalization and economic liberalization. The Annals of Regional Science, 35: 3-37.

Fujita M, Krugman P, Venables A, 1999. The Spatial Economy. Cambridge: MIT Press.

Hanson G H, 2001. Scale economies and the geographic concentration of industry. Journal of Economic Geography, 1(3): 255-276.

Harris C D, 1954. The market as a factor in the localization of industry in the United States. Annals of the Association of American Geographers, 44(4): 315-348.

He C F, Wang J S, 2012. Regional and sectoral differences in the spatial restructuring of Chinese manufacturing industries during the post-WTO period. GeoJournal, 77(3): 361-381.

He C F, Xie X Z, 2006. Geographical concentration and provincial specialization of Chinese manufacturing industries. Acta Geographica Sinica, 61(2): 212-222. (in Chinese)

He C F, Xie X Z, Pan F H, 2008. Locational studies of Chinese manufacturing industries. Geographical Research, 3(27): 623-635. (in Chinese)

Holmes T J, Stevens J J, 2004. Spatial distribution of economic activities in North America. Handbook of Regional and Urban Economics, 4: 2797-2843.

Huang J L, 2008. Market size and industrial growth in Chinese provinces. China Economic Quarterly, 4(7): 1317-1334. (in Chinese)

Huang J L, Li K W, 2006. Foreign trade, local protectionism and industrial location in China. China Economic Quarterly, 3(5): 733-760. (in Chinese)

Jin Y, Chen Z, Lu M, 2006. Industry agglomeration in China: Economic geography, new economic geography and policy. Economic Research Journal, 4: 79-89. (in Chinese)

Klein A, Crafts N, 2012. Making sense of the manufacturing belt: Determinants of US industrial location, 1880-1920. Journal of Economic Geography, 12(4): 775-807.

Kojima K, 2000. The "flying geese" model of Asian economic development: Origin, theoretical extensions, and regional policy implications. Journal of Asian Economics, 11(4): 375-401.

Krugman P, 1991. Increasing returns and economic geography. Journal of Political Economy, 99(3): 484-499.

Leamer E E, 1997. Access to western markets and eastern effort levels. In: Zecchini S (ed.). Lessons from the Economic Transition. Boston: Kluwer.

Lu D D, 1995. Regional Development and Its Spatial Structure. Beijing: Science Press. (in Chinese)

Lu J, Tao Z, 2009. Trends and determinants of China's industrial agglomeration. Journal of Urban Economics, 65(2): 167-180.

Midelfart-Knarvik K H, Overman HG, Redding S J et al., 2000. The location of European industry. European Commission. Directorate-General for Financial Affairs.

Venables A J, 1996. Equilibrium locations of vertically linked industries. International Economic Review: 341-359.

Vernon, 1966. International investment and international trade in the product cycle. The Quarterly Journal of Economics, 2(80): 190-207.

Vogiatzoglou K, 2006. Agglomeration or dispersion? Industrial specialization and geographic concentration in NAFTA. Journal of International Economic Studies, 20: 89-102.

Wang Y Q, Wei H K, 2007. Characteristics of industries, competition for space and the geographic concentration in manufacture. Management World, (4): 68-77. (in Chinese)

Wei B T, Zhou J W, 2008. Economic integration, regional specialization and spatial distribution of manufacturing in China. Economic Management, 19(30): 120-125. (in Chinese)

Wen M, 2004. Relocation and agglomeration of Chinese industry. Journal of Development Economics, 73(1): $329-347$.

Wu S M, Li S T, 2010. An analysis of spatial distribution of manufacturing industry in China. China Soft Science, 6: 123-131. (in Chinese)

Young A, 2000. The razor's edge: Distortions and incremental reform in the People's Republic of China. Quarterly Journal of Economics, 115(4): 1091-1135. 